\title{
Separation of Inorganic Anions Using Methacrylate-Based Monolithic Column Modified with Trimethylamine in Ion Chromatography Capillary System
}

\author{
Fitri Mairizki ${ }^{1}$, Athika Rahmah ${ }^{1}$, Hilma $^{1}$, Radhia Putri $^{1}$, Rahmiana Zein $^{1 *}$, \\ Lee Wah Lim², Toyohide Takeuchi ${ }^{2 *}$, Edison Munaf ${ }^{1}$ \\ ${ }^{1}$ Department of Chemistry, Faculty of Mathematics and Natural Sciences, Andalas Universiy, Padang, Indonesia \\ ${ }^{2}$ Department of Chemistry, Faculty of Engineering, Gifu University, Gifu, Japan \\ Email: "rzein@fmipa.unand.ac.id
}

Received June 12, 2013; revised July 12, 2013; accepted August 15, 2013

Copyright (C) 2013 Fitri Mairizki et al. This is an open access article distributed under the Creative Commons Attribution License, which permits unrestricted use, distribution, and reproduction in any medium, provided the original work is properly cited.

\begin{abstract}
Methacrylate-based monolithic column was prepared in fused-silica capillary $(80 \times 0.32 \mathrm{~mm}$ i.d. $)$ by in situ polymerizetion reaction using glycidyl methacrylate as monomer; ethylene dimethacrylate as crosslinker; 1-propanol, 1,4-butanediol, and water as porogenic solvents. The monolith matrix was modified with trimethylamine to create strong anion exchanger via ring opening reaction of epoxy groups. The morphology of the monolithic column was studied by using Scanning Electron Microscope (SEM). This column had good mechanical stability and permeability. The effects of various mobile phases for separation of inorganic anions were investigated. Iodate, bromate, nitrite, bromide, and nitrate were separated within 11 min using $100 \mathrm{mM}$ potassium chloride as mobile phase and detected at $210 \mathrm{~nm}$. This method showed good precision of retention time, acceptable linearity and good sensitivity. Under the optimum condition, the RSD of the retention time was in the range of $1.09 \%-1.75 \%(n=6)$. The calibration curve showed linear relationships between the peak area and the concentration. The limits of detection (LOD) and the limits of quantitation (LOQ) were between $0.08-0.18 \mathrm{mM}$ and $0.26-0.61 \mathrm{mM}$, respectively. This method was applied to the determination of inorganic anions in tap water and ground water samples.
\end{abstract}

Keywords: Methacrylate-Based Monolithic Column; Trimethylamine; Ion Chromatography Capillary System; Inorganic Anions; Water Sample

\section{Introduction}

Ion chromatography was first introduced by Small, et al. in 1975 as a new analytical method. In a short time, ion chromatography has grown rapidly as one of the technologies for the separation and determination of inorganic anions and cations, carbohydrates, small organic compounds, peptides or proteins. In ion chromatography, the stationary phases have a functional group that will interact with the ionic analytes through electrostatic interactions so as the ionic analytes can be separated [1]. Zein, et al. and Munaf, et al. [2,3] developed bovine serum albumin as a stationary phase for the separation of inorganic anions. A few papers also have been reported for the simultaneous separation of anions and cations [4-6].

Various types of stationary phase have been developed

${ }^{*}$ Corresponding author. for the separation of ionic species. In recent years, monolithic columns have attracted much attention as the separation media in chromatography. Monolithic columns in capillary liquid chromatography were introduced by Hjerten, et al. in 1989, and since that time, monolithic columns have rapidly become highly popular [7]. Monolithic columns have many unique properties. They have porous structure with bimodal pore size distribution, $\mathrm{nm}$-sized mesopores at the surface of the skeletal structure and $\mu \mathrm{m}$-sized through pores (macropores) between the skeletal structure. The nm-sized mesopores can give sufficient surface area, which have a positive effect on separation efficiency. On the other hand, the $\mu \mathrm{m}$-sized through pores generate low-pressure drop and enhance mass transfer kinetics which can allow the use of higher flow rates for rapid separations on relatively long columns [8]. The diffusion path length and flow resistance can be reduced using monolithic columns compared with 
a particle-packed. The ease of preparation and availability of various precursors also contributes to the popularity of monoliths [9].

A greater chromatography efficiency is shown by the monolithic columns for the separation of macromolecules such as nucleotides, oligonucleotides [10], peptides [11] and proteins [12-15]. Therefore, the monolithic colums have been applied in environmental, pharmaceutical, and genomic applications [16]. Recently, a few researchers began to explore the monolithic columns application for the separation of small organic molecules [17-19], and inorganic molecules such as ionic species [20,21].

In general, there are two types of monolithic columns which have been developed for chromatography: silica-based monolithic column [22-24] and organic polymer-based monolithic column $[25,26]$. Silica-based monolithic columns are produced by using the sol-gel approach to make a continuous sol-gel network throughout the column. On the other hand, organic polymer-based monolithic columns are produced by in situ polymerization. The polymerization reaction mixtures consist of a combination of an initiator, monomers, cross-linkers and porogens [27]. The organic polymer-based monolithic columns have some advantages compared with silica-based monolithic columns, including simple preparation process, high stability over a wide $\mathrm{pH}$ range and easily modified for different purposes [28,29]. However, the organic polymer-based monolithic column applications for separation of ionic species had still remained a challenge in ion chromatography.

There are three types of organic polymer-based monolithic columns: acrylamide-based, methacrylate-based, and styrene-based polymers [30]. The methacrylate-based polymers have some advantages related with their use as stationary phase in monolithic columns, such as simple preparation, easy functionalization, various selectivity, and high stability under extreme $\mathrm{pH}$ conditions ( $\mathrm{pH} 2$ or 12) [31,32]. The combination of their properties makes methacrylate-based monolithic columns become new interesting opportunities in chromatography for the analysis of complex matrices and fast separation [33].

In this work, we use glycidyl methacrylate as monomer to prepare methacrylate-based monolithic column, because it has highly reactive epoxy ring which could be easily converted into anion exchange group via ring opening reaction. The present paper describes the use of methacrylate-based monolithic column which modified with trimethylamine to produce a strong anion exchanger for separation of inorganic anions.

\section{Experimental}

\subsection{Apparatus}

Chromatographic evaluation was performed using a microfeeder (L. TEX Corporation, Tokyo, Japan) equipped with a gas-tight syringe $(0.5 \mathrm{~mL}$; Ito, Fuji, Japan $)$ as a pump, a micro valve injector with an injection volume $0.2 \mu \mathrm{L}$ (Upchurch Scientific, Oak Harbor, WA, USA), a $80 \times 0.32 \mathrm{~mm}$ i.d. as a separation column (GL Science, Tokyo, Japan), a UV detector (Jasco, Japan) with a modified flow cell and Chromatopac C-R7Ae as a recorder (Shimadzu, Kyoto, Japan). The flow rate of the mobile phase was kept constant at $4 \mu \mathrm{L} \cdot \mathrm{min}^{-1}$. Scanning electron micrographic images for morphology observation of the monolithic column were obtained using a SEM S-4800 (Hitachi, Japan).

\subsection{Chemicals}

All chemicals used were of analytical grade. 2,2'-azo-bis (isobuthyronitrile) (AIBN), glycidyl methacrylate (GMA) and ethylene dimethacrylate (EDMA) were purchased from Wako Pure Chemical Industries (Osaka, Japan). 1-propanol and 1,4-butanediol were obtained from Nacalai Tesque (Kyoto, Japan). Trimethylamine (30 wt \% in $\mathrm{H}_{2} \mathrm{O}$ ) and tetrahydrofuran were from Kanto Chemical (Tokyo, Japan). The purified water was prepared using GS-590 water distillation system (Advantec, Tokyo, Japan). Other chemicals were used as received.

\subsection{Preparation of Methacrylate-Based Anion-Exchange Monolithic Column}

The fused silica capillary was first activated by $1 \mathrm{~mol} \cdot \mathrm{L}^{-1}$ $\mathrm{NaOH}$, purified water, and $1 \mathrm{~mol} \cdot \mathrm{L}^{-1} \mathrm{HCl}$. 3-(trimethoxysilyl)-propyl methacrylate ( $\gamma$-MAPS) solution $(30 \%(\mathrm{v} / \mathrm{v})$ in aceton) was used to fill the activated capillary. After sealing the capillary two ends, the reaction was allowed to perform $60^{\circ} \mathrm{C}$ for $24 \mathrm{~h}$ in waterbath. Then, the capillary was washed thoroughly with aceton. The N2 was flown through the capillary to dry the inner surface before further use.

The monolithic column was prepared by in situ polymerization. A polymerization mixture containing GMA (30\% (v/v)), EDMA (10\% (v/v)), 1-propanol (35\% (v/v)), 1,4-butanediol $(20 \%(\mathrm{v} / \mathrm{v}))$, water $(5 \%(\mathrm{v} / \mathrm{v}))$, and AIBN $(1 \%(\mathrm{w} / \mathrm{v})$ of the total monomer amount). This mixture solution was ultrasonically homogenized for $5 \mathrm{~min}$ and immediately aspirated into the pretreated capillary. After sealing both ends, the treated capillary was placed in the waterbath to proceeds the polymerization at $60^{\circ} \mathrm{C}$ for 24 h. The monolith was washed with methanol to remove the unreacted monomers and remaining porogenic solvent present in the column. Subsequently, epoxy groups in the monolith were reacted with trimethylamine to get strong anion exchanger, as the following procedure: a trimethylamine solution $(50 \%(\mathrm{v} / \mathrm{v})$ in tetrahydrofuran) was passed through the monolithic column at flow rate 4 $\mu \mathrm{L} \cdot \mathrm{min}^{-1}$ for $2 \mathrm{~h}$. Then, the monolithic column was placed in the oven to proceeds the modification at $80^{\circ} \mathrm{C}$ 
for $5 \mathrm{~h}$. The anion exchange monolithic column produced was washed with methanol for $3 \mathrm{~h}$ at $2 \mu \mathrm{L} \cdot \mathrm{min}^{-1}$ of flow rate.

\section{Results and Discussion}

\subsection{Preparation of Methacrylate-Based Anion-Exchange Monolithic Column}

The monolithic column was prepared directly in the capillary by in situ polymerization method. There are two step were adopted in this experiment to form the polymer network. First, the synthesis of a rigid polymer matrix by using GMA as monomer, EDMA as crosslinker, and ternary porogen which consists of 1-propanol, 1,4-butanediol, and water. Then, the introduction of trimethylamine as strong anion exchange moiety via ring-opening reaction of the epoxy group. The composition of the monomer, crosslinker, porogen solvent; polymerization reaction time; and modification conditions would have great effect on the monolithic structure.

The morphology of the monolithic column was an important parameter that can affect the capability and efficiency separation. The morphology of the monolithic column was examined by scanning electron microscopy (SEM). Figure 1(a) demonstrates that the morphology of monolithic column were solid and completely attached to

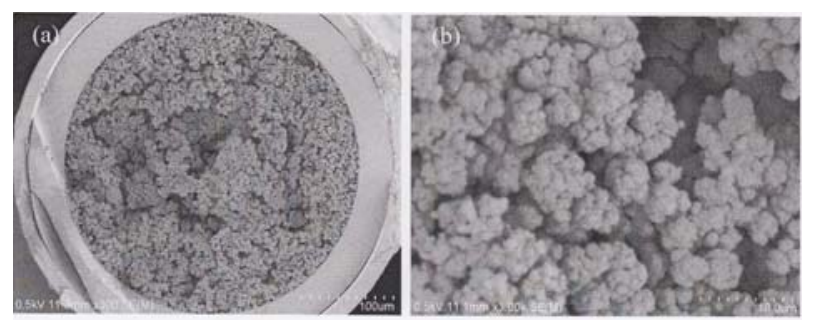

Figure 1. Scanning electron microphotographs of monolithic column. (a) Wide-view and (b) close-up-view.

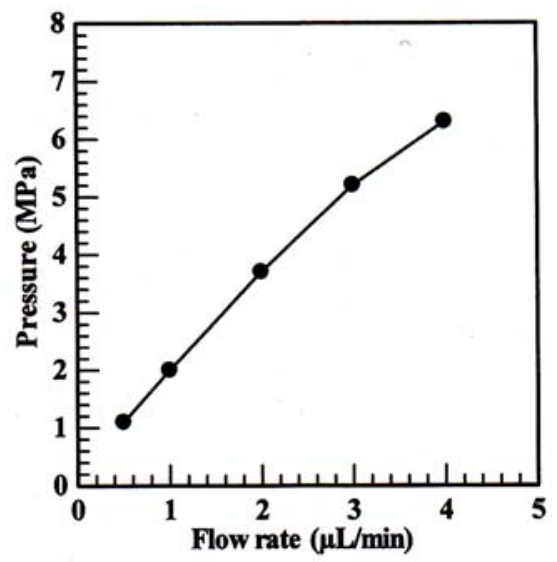

Figure 2. Plots of the flow rate of water against the back pressure of the monolithic column. Column, $80 \times 0.32 \mathrm{~mm}$ i.d.; mobile phase: water. the inner surface of the capillary column. It indicated that the monolith was covalently bonded to the capillary. The successful attachment of monolith into the inner surface of the capillary column influenced by the pre-treatment step of the capillary column. As shown in Figure 2(b), the obtained monolith displayed porous network with globular structure. The continuous porous channels in the monolith bed which were formed by mesopores and through pores can also be seen.

The permeability of monolithic column was examined by measure the back pressure for different flow rate using water as mobile phase. The flow rate ranged from 0.5 to $4 \mu \mathrm{L} \cdot \mathrm{min}^{-1}$. Column permeability is affected by amount of porogenic solvent. A sufficient amount of porogen would result good permeability so as the mobile phase and sample solution would flow through the column under small back pressure. On the contrary, insufficient amount of porogen would make the mobile phase and sample solution flow through the column under large back pressure [34]. The permeability of the monolithic column was calculated as $9.88 \times 10^{-13} \cdot \mathrm{m}^{2}$ which indicated that the monolithic column had good permeability. The permeability $\left(B_{0}\right)$ was calculated by using Darcy's Law [35],

$$
B_{0}=F \eta L /\left(\pi r^{2} \Delta P\right)
$$

where $F$ was the linear velocity of the mobile phase, $\eta$ was the dynamic viscosity of the mobile phase $(\eta=0.089$ Pa s for water), $L$ was the effective column length, and $\Delta \mathrm{P}$ was pressure drop.

On the other hand, the back pressures dependence on flow rate was a straight line with a correlation coefficient $\mathrm{R}^{2} 0.992$ (Figure 2), which indicated the good mechanical stability of the prepared monolithic column.

\subsection{Separation of Inorganic Anions}

Three anions were first used to evaluate the performances of the monolithic column. Figure 3 demonstrates the separation of three inorganic anions on monolithic column using various mobile phases with the same concentration. The analytes are detected at $210 \mathrm{~nm}$. All the analytes can well separated. Potassium chloride provided better resolution of the anions in a shorter retention time and more reproducible signals than the others.

In order to increase the retention time of analytes, the concentration of the mobile phase should be higher. Potassium chloride was examined as the mobile phase in the $50-200 \mathrm{mM}$ concentration range. Separations of five inorganic anions were shown in Figure 4. The elution order was iodate, bromate, nitrite, bromide and nitrate. The present system is more sensitive to determination of iodate, nitrite and nitrate compared with bromate and bromide. It's seen that, the retention time of analytes could be increase with the increasing of the mobile phase 


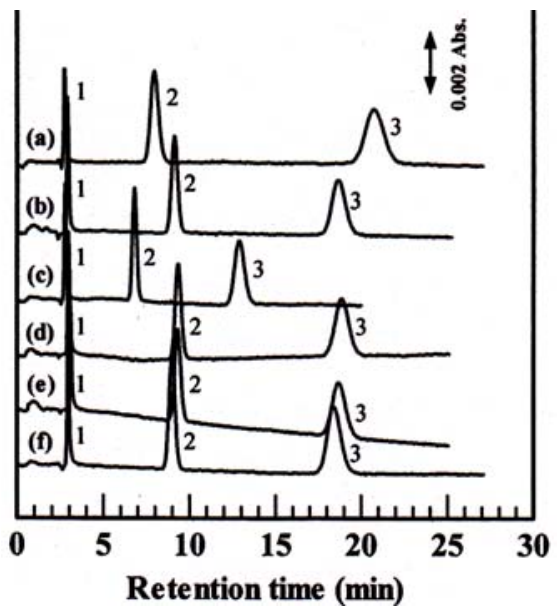

Figure 3. Effect of the mobile phase on the separation of inorganic anions. Column, $80 \times 0.32 \mathbf{~ m m}$ i.d.; mobile phase: $50 \mathrm{mM} \mathrm{LiCl} 50$ (a), $50 \mathrm{mM} \mathrm{NaCl}$ (b), $50 \mathrm{mM} \mathrm{KCl}$ (c), 50 $\mathrm{mM} \mathrm{RbCl} \mathrm{(d),} 50 \mathrm{mM} \mathrm{CsCl}$ (e), $50 \mathrm{mM} \mathrm{NH}_{4} \mathrm{Cl}$ (f); flow rate: $4 \mu \mathrm{L} \cdot \mathrm{min}^{-1}$; injection volume, $0.2 \mu \mathrm{L}$; wavelength of $\mathrm{UV}$ detection: $210 \mathrm{~nm}$; analytes: $1=$ iodate, $2=$ nitrite, $3=$ nitrate, $1.0 \mathrm{mM}$ each.

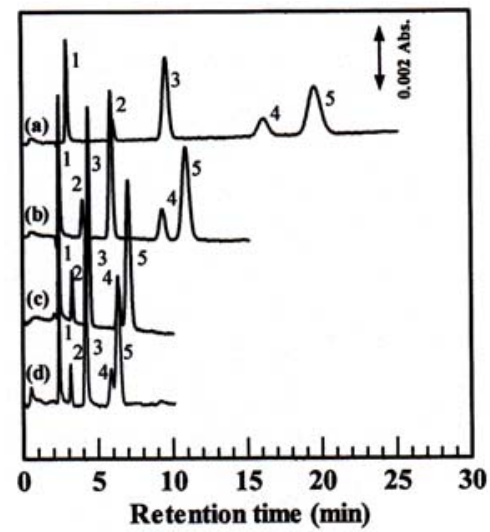

Figure 4. Effect of concentration of potassium chloride mobile phase on the separation of inorganic anions. Column dimension: $80 \times 0.32 \mathrm{~mm}$ i.d.; concentration of mobile phase: (a). $50 \mathrm{mM}$, (b). $100 \mathrm{mM} \mathrm{KCl,} \mathrm{(c).} 150 \mathrm{mM}$, (d). $200 \mathrm{mM}$; flow rate: $4 \mu \mathrm{L} \cdot \mathrm{min}^{-1}$; injection volume: $0.2 \mu \mathrm{L}$; wavelength of $\mathrm{UV}$ detection, $210 \mathrm{~nm}$; analytes, 1 = iodate, 2 = bromate, $3=$ nitrite, $4=$ bromide, $5=$ nitrate, $1.0 \mathrm{mM}$ each.

concentration. On the other hand, if the concentration of the mobile phase was too high, the analytes could not be separated completely. Considering the experimental results, $100 \mathrm{mM}$ of potassium chloride was selected as a mobile phase for the following experiments.

\subsection{Analytical Figures of Merit}

The RSD of the retention time for the six succescive chromatographic run under the optimum condition were in the $1.09 \%-1.75 \%$ range. The RSD for the retention time were less than $2 \%$. It showed that this method had good repeatability.

The calibration curves of the five inorganic anions are shown in Figure 5. The calibration graphs showed linear relationships between the peak area and the concentration. It can be seen from the good R-square values obtained.

The limits of detection (LOD) were $0.15,0.18,0.14$, $0.15,0.08 \mathrm{mM}$ for iodate, bromate, nitrite, bromide, nitrate, respectively. On the other hand, the limits of quantitation (LOQ) of iodate, bromate, nitrite, bromide, nitrate were $0.50,0.61,0.46,0.49,0.26 \mathrm{mM}$, respectively. The values of LOD and LOQ were low enough. It showed that this method had good sensitivity.

\subsection{Practical Application}

The monolithic column was applied to the determination of inorganic anions present in tap water and ground water water samples. The results are shown in Figure 6. There were no inorganic anions identified in the tap water sam

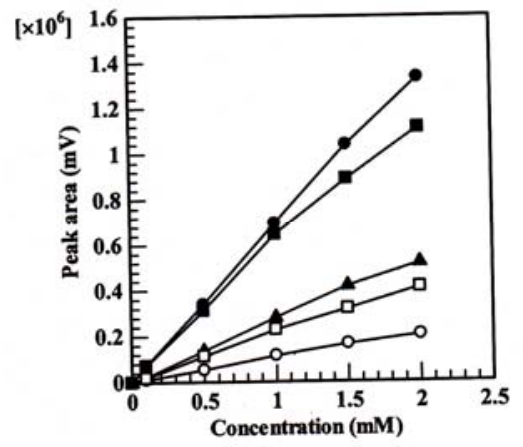

Figure 5. Calibration curves for five inorganic anions. Colu$\mathrm{mn}, 80 \times 0.32 \mathrm{~mm}$ i.d.; mobile phase, $100 \mathrm{mM} \mathrm{KCl}$; flow rate, $4 \mu \mathrm{L}$ min-1; injection volume: $0.2 \mu \mathrm{L}$; wavelength of UV detection: $210 \mathrm{~nm}$; $\boldsymbol{\Delta}$ = iodate, $\bigcirc=$ bromate, $\boldsymbol{\square}=$ nitrite, $\square=$ bromide, $\bullet=$ nitrate.

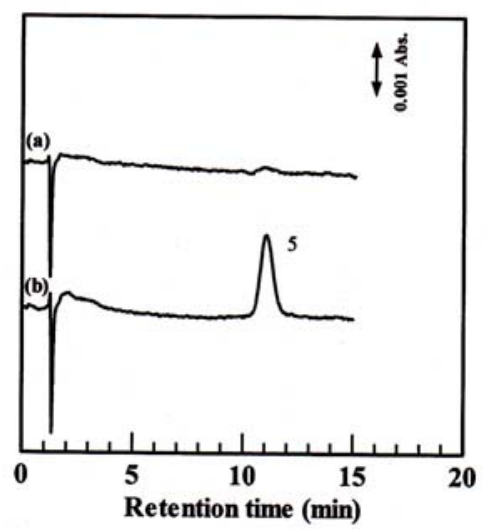

Figure 6. Separation of inorganic anions in water samples. Column dimension: $80 \times 0.32 \mathrm{~mm}$ i.d.; mobile phase: 100 mM KCl; flow rate: $4 \mu \mathrm{L} \cdot \mathrm{min}^{-1}$; injection volume: $0.2 \mu \mathrm{L}$; wavelength of $U V$ detection, $210 \mathrm{~nm}$; sample: tap water (a) and ground water samples (b). 
ple (Figure 6(a)). On the other hand, nitrate was identified in the ground water sample (Figure 6(b)), with concentration of nitrate is $0.08 \mathrm{mM}$. The concentration of nitrate as calculated according to the peak area was 0.08 $\mathrm{mM}$.

\section{Conclusion}

A poly(glycidyl methacrylate-co-ethylene dimethacrylate) anion exchange monolithic column was successfully produced by in situ polymerization further modified with trimethylamine via ring-opening reaction of epoxy group. Morphology of the monolithic column was studied by scanning electron microscopy. Mechanical stability and permeability of the column were both good. In general, this method provides good precision of retention time, acceptable linearity and good sensitivity. The present method could be applied to the determination of inorganic anions contained in tap water and ground water with the good values for recovery.

\section{Acknowledgements}

The authors gratefully acknowledge the Japan Student Services Organization (JASSO) for the scholarships over. The authors would like also to thank to the Dean of Faculty of Engineering, Gifu University, Japan and the Dean of Faculty of Mathematics and Natural Sciences, Andalas University, Indonesia, for their generous support.

\section{REFERENCES}

[1] A. Sedyohutomo, H. Suzuki and C. Fujimoto, "Determination of Inorganic Anions by Capillary Ion-Exchange Chromatography Using Polyethylenimine-coated Octadecyl-Bonded Phases," Analytical Sciences, Vol. 28, No. 6, 2012, pp. 625-629. doi:10.2116/analsci.28.625

[2] R. Zein, E. Munaf, T. Takeuchi and T. Miwa, "Microcolumn Ion Chromatography of Inorganic UV-Absorbing Anions Using Bovine Serum Albumin as Stationary Phases," Analytica Chimica Acta, Vol. 335, No. 3, 1996, pp. 261-266. doi:10.1016/S0003-2670(96)00383-2

[3] E. Munaf, R. Zein, T. Takeuchi and T. Miwa, "Microcolumn Ion Chromatography of Inorganic Anions Using Bovine Serum Albumin Stationary Phase with Indirect Photometric Detection," Chromatographia, Vol. 43, No. 5-6, 1996, pp. 304-308. doi:10.1007/BF02271000

[4] T. Takeuchi, Safni, T. Miwa, Y. Hashimoto and H. Moriyama, "Ion Chromatography Using Anion Exchangers Modified with Heparin," Analusis, Vol. 26, No. 2, 1998, pp. 61-64. doi:10.1051/analusis:1998111

[5] M. G. Kiseleva, P. A. Kebets and P. N. Nesterenko, "Simultaneous Ion Chromatographic Separation of Anions and Cations on Poly(aspartic acid) Functionalized Silica," Analyst, Vol. 126, No. 12, 2001, pp. 2119-2123. doi: $10.1039 / \mathrm{b} 106283 \mathrm{~m}$

[6] M. Amin, L. W. Lim and T. Takeuchi, "Peak Parking
Technique for The Simultaneous Determination of Anions and Cations," Analytical and Bioanalytical Chemistry, Vol. 381, No. 7, 2005, pp. 1426-1431. doi:10.1007/s00216-005-3073-Z

[7] Z. A. AlOthman, A. Aqel, H. A. Al Abdelmoneim, A.Y. Badjah-Hadj-Ahmed and A. A. Al-Warthan, "Preparation and Evaluation of Long Chain Alkyl Methacrylate Monoliths for Capillary Chromatography," Chromatographia, Vol. 74, No. 1, 2011, pp. 1-8.

[8] A. Sabarudin, J. Huang, S. Shu, S. Sakagawa and T. Umemura, "Preparation of Methacrylate-based AnionExchange Monolithic Microbore Column for Chromatographic Separation of DNA Fragments and Oligonucleotides," Analytica Chimica Acta, Vol. 736, 2012, pp. 108114. doi:10.1016/j.aca.2012.05.039

[9] N. Wang, S. He and Y. Zhu, "Low-Level Bromate Analysis by Ion Chromatography on a Polymethacrylate-based Monolithic Column Followed by a Post-Column Reaction," European Food Research and Technology, Vol. 235, No. 4, 2012, pp. 685-692. doi:10.1007/s00217-012-1800-1

[10] T. A. E. Jakschitz, C.W. Huck, S. Lubbad and G. K. Bonn, "Monolithic Poly[(trimethylsilyl-4-methylstyrene)-co-bis (4-vinylbenzyl) dimethylsilane] Stationary Phases for the Fast Separation of Proteins and Oligonucleotides," Journal of Chromatography A, Vol. 1147, No. 1, 2007, pp. 53-58. doi:10.1016/i.chroma.2007.02.078

[11] P. Pruim, M. Ohman, Y. Huo, P. J. Schoenmakers and W.Th. Kok, "Methacrylate Monolithic Capillary Columns for Gradient Peptide Separations," Journal of Chromatography A, Vol. 1208, No. 1-2, 2008, pp. 109-115. doi:10.1016/j.chroma.2008.08.069

[12] B. Gu, J. M. Armenta and M. L. Lee, "Preparation and Evaluation of Poly(polyethylene glycol methylether acrylate-co-polyethylene glycol diacrylate) Monolith for Protein Analysis," Journal of Chromatography A, Vol. 1079, No. 1-2, 2005, pp. 382-391. doi:10.1016/j.chroma.2005.02.088

[13] Y. Li, B. Gu, H. D. Tolley and M. L. Lee, "Preparation of Polymeric Monoliths by Copolymerization of Acrylate Monomers with Amine Functionalities for Anion-exchange Capillary Liquid Chromatography of Proteins," Journal of Chromatography A, Vol. 1216, No. 29, 2009, pp. 5525-5532. doi:10.1016/j.chroma.2009.05.037

[14] J. Krenkova, A. Gargano, N. A. Lacher, J. M. Schneiderheinze and F. Svec, "High Binding Capacity Surface Grafted Monolithic Columns for Cation Exchange Chromatography of Proteins and Peptides," Journal of Chromatography A, Vol. 1216, No. 40, 2009, pp. 6824-6830. doi:10.1016/j.chroma.2009.08.031

[15] X. Chen, H. D. Tolley and M. L. Lee, "Monolithic Capillary Columns Synthesized from a Single Phosphate-containing Dimethacrylate Monomer for Cation-exchange Chromatography of Peptides and Proteins," Journal of Chromatography A, Vol. 1218, No. 28, 2011, pp. 43224331. doi:10.1016/j.chroma.2011.04.074

[16] C. Gu, L. Lin, X. Chen, J. Jia, J. Ren and N. Fang, "Fabrication of a Poly(styrene-octadecene-divinylbenzene) Monolithic Column and Its Comparison with a Poly(sty- 
rene-divinylbenzene) Monolithic Column for The Separation of Proteins," Journal of Separation Science, Vol. 30, No. 7, 2007, pp. 1005-1012. doi:10.1002/jssc. 200600397

[17] T. Hirano, S. Kitagawa and H. Ohtani, "Methacrylate-Ester-Based Reversed Phase Monolithic Columns for High Speed Separation Prepared by Low Temperature UV Photo-polymerization," Analytical Sciences, Vol. 25, No. 9, 2009, pp. 1107-1113. doi:10.2116/analsci.25.1107

[18] I. Nischang and O. Bruggemann, "On the Separation of Small Molecules by Means of Nano-Liquid Chromatography with Methacrylate-Based Macroporous Polymer Monoliths," Journal of Chromatography A, Vol. 1217, No. 33, 2010, pp. 5389-5397. doi:10.1016/j.chroma.2010.06.021

[19] A. Svobodova, T. Krizek, J. Sirc, P. Salek, E. Tesarova, P. Coufal and K. Stulik, "Monolithic Columns Based on a Poly(styrene-divinylbenzene-methacrylic acid) Copolymer for Capillary Liquid Chromatography of Small Organic Molecules," Journal of Chromatography A. Vol. 1218, No. 11, 2011, pp. 1544-1547. doi:10.1016/j.chroma.2011.01.042

[20] A. Suzuki, L. W. Lim and T. Takeuchi, "Rapid Separation of Inorganic Anions by Capillary Ion Chromatography Using Monolithic Silica Columns Modified with Dilauryldimethylammonium Ion," Analytical Sciences, Vo. 23, No. 9, 2007, pp. 1081-1084. doi:10.2116/analsci.23.1081

[21] M. Takahashi, T. Hirano, S. Kitagawa and H. Ohtani, "Separation of Small Inorganic Anions Using Methacrylate-based anion-exchange Monolithic Column Prepared by Low Temperature UV Photo-polymerization," Journal of Chromatography A, Vol. 1232, 2012, pp. 123-127. doi:10.1016/j.chroma.2011.10.070

[22] M. Motokawa, H. Kobayashi, N. Ishizuka, H. Minakuchi, K. Nakanishi, H. Jinnai, K. Hosoya, T. Ikegami and N. Tanaka, "Monolithic Silica Columns with Various Skeleton Sizes and Through-pore Sizes for Capillary Liquid Chromatography," Journal of Chromatography A, Vol. 961, No. 1, 2002, pp. 53-63. doi:10.1016/S0021-9673(02)00133-4

[23] K. M. Glenn, C. A. Lucy and P. R. Haddad, "Ion Chromatography on a Latex-coated Silica Monolith Column, Journal of Chromatography A, Vol. 1155, No. 1, 2007, pp. 8-14. doi:10.1016/i.chroma.2007.01.098

[24] M. Rogeberg, S. R. Wilson, H. Malerod, E. Lundanes, N. Tanaka and T. Greibrokk, "High Efficiency, High Temperature Separations on Silica Based Monolithic Columns," Journal of Chromatography A, Vol. 1218, No. 41, 2011, pp. 7281-7288. doi:10.1016/j.chroma.2011.08.049

[25] R. Shediac, S. M. Ngola, D. J. Throckmorton, D. S. Anex, T. J. Shepodd and A. K. Singh, "Reversed-phase Electrochromatography of Amino Acids and Peptides Using Porous Polymer Monoliths," Journal of Chromatography A, Vol. 925, No. 1-2, 2001, pp. 251-263. doi:10.1016/S0021-9673(01)01036-6

[26] C. J. Evenhuis, W. Buchberger, E. F. Hilder, K. J. Flook,
C. A. Pohl, P. N. Nesterenko and P. R. Haddad, "Separation of Inorganic Anions on a High Capacity Porous Polymeric Monolithic Column and Application to Direct Determination of Anions in Seawater," Journal of Separation Science, Vol. 31, No. 14, 2008, pp. 2598-2604. doi:10.1002/jssc.200800205

[27] D. Moravcova, P. Jandera, J. Urban and J. Planeta, "Comparison of Monolithic Silica and Polymethacrylate Capillary Columns for LC," Journal of Separation Science, Vol. 27, No. 10-11, 2004, pp. 789-800. doi: $10.1002 /$ issc. 200401778

[28] T. Nakaza, A. Kobayashi, T. Hirano, S. Kitagawa and H. Ohtani, "Determination of Monomer Conversion in Methacrylate-based Polymer Monoliths Fixed in a Capillary Column by Pyrolysis-Gas Chromatography," Analytical Sciences, Vol. 28, No. 9, 2012, pp. 917-920. doi:10.2116/analsci.28.917

[29] Y. Zhong, W. Zhou, P. Zhang and Y. Zhu, "Preparation, Characterization, and Analytical Applications of a Novel Polymer Stationary Phase with Embedded or Grafted Carbon Fibers," Talanta, Vol. 82, No. 4, 2010, pp. 1439 1447. doi:10.1016/j.talanta.2010.07.019

[30] Y. Huo, P. J. Schoenmakers and W. Th. Kok, "Efficiency of Methacrylate Monolithic Columns in Reversed-phase Liquid Chromatographic Separations," Journal of Chromatography A, Vol. 1175, No. 1, 2007, pp. 81-88. doi:10.1016/j.chroma.2007.10.048

[31] D. Moravcova, P. Jandera, J. Urban and J. Planeta, "Characterization of Polymer Monolithic Stationary Phases for Capillary HPLC," Journal of Separation Science, Vol. 26, No. 11, 2003, pp. 1005-1016. doi:10.1002/jssc. 200301498

[32] X. Shu, L. Chen, B. Yang and Y. Guan, "Preparation and Characterization of Long Methacrylate Monolithic Column for Capillary Liquid Chromatography," Journal of Chromatography A, Vol. 1052, No. 1-2, 2004, pp. 205209. doi:10.1016/j.chroma.2004.08.099

[33] A. Bruchet, V. Dugas, C. Mariet, F. Goutelard and J. Randon, "Improved Chromatographic Performances of Glycidyl Methacrylate Anion-exchange Monolith for Fast Nano-ion Exchange Chromatography," Journal of Separation Science, Vol. 34, No. 16-17, 2011, pp. 2079-2087.

[34] Y. Fan, Y. Q. Feng, S. L. Da and Z. G. Shi, "Poly (methacrylic acid-ethylene glycol dimethacrylate) Monolithic Capillary for In-tube Solid Phase Microextraction Coupled to High Performance Liquid Chromatography and Its Application to Determination of Basic Drugs in Human Serum," Analytica Chimica Acta, Vol. 523, No. 2, 2004, pp. 251-258. doi:10.1016/j.aca.2004.07.052

[35] M. Wu, R. Wu, R. Li, H. Qin, J. Dong, Z. Zhang and H. Zou, "Polyhedral Oligomeric Silsesquioxane as a CrossLinker for Preparation of Inorganic-Organic Hybrid Monolithic Columns," Analytical Chemistry, Vol. 82, No. 13, 2010, pp. 5447-5454. doi:10.1021/ac1003147 